\title{
Drosophila poised enhancers are generated during tissue patterning with the help of repression
}

\author{
Nina Koenecke, ${ }^{1}$ Jeff Johnston, ${ }^{1,3}$ Qiye He, ${ }^{1,4}$ Samuel Meier, ${ }^{1,5}$ and Julia Zeitlinger ${ }^{1,2}$ \\ ${ }^{1}$ Stowers Institute for Medical Research, Kansas City, Missouri 64110, USA; ${ }^{2}$ University of Kansas Medical Center, \\ Department of Pathology, Kansas City, Kansas 66160, USA
}

\begin{abstract}
Histone modifications are frequently used as markers for enhancer states, but how to interpret enhancer states in the context of embryonic development is not clear. The poised enhancer signature, involving H3K4mel and low levels of H3K27ac, has been reported to mark inactive enhancers that are poised for future activation. However, future activation is not always observed, and alternative reasons for the widespread occurrence of this enhancer signature have not been investigated. By analyzing enhancers during dorsal-ventral (DV) axis formation in the Drosophila embryo, we find that the poised enhancer signature is specifically generated during patterning in the tissue where the enhancers are not induced, including at enhancers that are known to be repressed by a transcriptional repressor. These results suggest that, rather than serving exclusively as an intermediate step before future activation, the poised enhancer state may be a mark for spatial regulation during tissue patterning. We discuss the possibility that the poised enhancer state is more generally the result of repression by transcriptional repressors.
\end{abstract}

[Supplemental material is available for this article.]

Understanding the mechanisms by which cis-regulatory elements, or enhancers, activate transcription has been intensively studied for the last three decades, yet our knowledge remains incomplete (Shlyueva et al. 2014). As shown by ChIP-seq experiments, transcription factors may bind to thousands of putative enhancer regions in the genome (Moorman et al. 2006; Li et al. 2008), yet a large fraction of these regions are likely inactive for a variety of reasons. For example, transcription factors may bind to so-called primed enhancers that have been made accessible by pioneer transcription factors but are not yet active (Zaret and Carroll 2011; Spitz and Furlong 2012), or they may bind to repressed enhancers, which are bound and actively prevented from activation by sequence-specific repressors (Sandmann et al. 2007; Zeitlinger et al. 2007). This raises the question of what types of enhancer states exist, how they relate to each other, and how they help regulate the complex spatial and temporal expression patterns of genes during the development of multicellular organisms.

Good markers for enhancer states are the histone modifications found at the nucleosomes flanking enhancer regions. Most open enhancer regions are marked by histone monomethylation on lysine 4 of histone H3 (H3K4me1), but only active enhancers carry lysine 27 acetylation on histone H3 (H3K27ac) (Creyghton et al. 2010; Ernst et al. 2011; Rada-Iglesias et al. 2011; Zentner et al. 2011; Bonn et al. 2012). Since some inactive enhancers show activation during later development, the combination of H3K4me1 along with low H3K27ac at inactive enhancers was termed the poised enhancer signature (Creyghton et al. 2010; Rada-Iglesias et al. 2011).

Present addresses: ${ }^{3}$ Center for Pediatric Genomic Medicine, Children's Mercy Hospital, Kansas City, MO 64108, USA: ${ }^{4}$ Department of Basic Medicine, School of Medical Sciences, Zhejiang University, Hangzhou, Zhejiang Province 310058, China; ${ }^{5}$ Broad Institute, Cambridge, MA 02142, USA

Corresponding author: jbz@stowers.org

Article published online before print. Article, supplemental material, and publication date are at http://www.genome.org/cgi/doi/10.1101/gr.209486.116. Freely available online through the Genome Research Open Access option.
The mechanisms by which poised enhancers remain inactive and by which they become active under some conditions are poorly understood. For example, some studies have implicated the Polycomb-repressive mark H3K27me3 as a marker for poised enhancers (Rada-Iglesias et al. 2011), while others have not (Creyghton et al. 2010; Bonn et al. 2012). It is also possible that other mechanisms of repression might make enhancers susceptible to de-repression, thereby poising them for activation, but the relationship between poised enhancers and repressed enhancers has not yet been examined.

Poised enhancers are very common during the development of Drosophila and mammalian lineages, but their role in tissue patterning and lineage specification remains unclear. While originally described as being poised for future activation, this model is likely an oversimplification. The majority of enhancers become active without going through a poised state during prior developmental stages (Bonn et al. 2012; Choukrallah et al. 2015). Only a small fraction of poised enhancers are usually activated during lineage development (Rada-Iglesias et al. 2011; Bonn et al. 2012; Wamstad et al. 2012). Instead, many enhancers that are poised in a cell type are active in related cell types (Bonn et al. 2012; Junion et al. 2012; Wang et al. 2015). This not only questions the strict temporal model in which the poised enhancer state precedes enhancer activation but also suggests a role for poised enhancers in tissue patterning.

A widespread role for poised enhancers in tissue patterning is consistent with large-scale DNase hypersensitivity (DHS) assays across a variety of cell types representing stages of human development (Stergachis et al. 2013). These data also show that enhancers are frequently accessible across broadly related cell types and only become active in specific lineages, raising the possibility that poised enhancers in embryonic tissues are predisposed for activation spatially and that enhancer activation is regulated by signals that control pattern formation.

(C) 2017 Koenecke et al. This article, published in Genome Research, is available under a Creative Commons License (Attribution-NonCommercial 4.0 International), as described at http://creativecommons.org/licenses/by-nc/4.0/. 
During tissue patterning, developmental signals (or morphogens) are often generated at and propagated from precise locations within the embryo, typically leading to the graded activation of signal transduction pathways and transcription factors across fields of cells (Briscoe and Small 2015). Depending on the strength of signaling, different target genes are activated, giving rise to distinct cell fates across the gradient. Activation of already accessible enhancers is a logical mechanism by which signal transduction pathways could mediate precise cellular responses to morphogens. The broad distribution of poised enhancers may ensure that a sufficient number of cells can respond to specific developmental signals in the appropriate manner, thus facilitating pattern formation.

While a function of poised enhancers in pattern formation is plausible, in many systems the hypothesis is difficult to test due to the scarcity and heterogeneity of embryonic tissues. To analyze a possible role for poised enhancers during pattern formation in the embryo, we used the tractable Drosophila dorso-ventral (DV) patterning as a model system. In the Drosophila embryo, DV patterning begins with localized activation of the Toll (Tl) receptor by maternal components, which leads to the formation of a morphogen gradient of the transcription factor Dorsal (Dl) and gives rise to at least three cell fates with distinct gene expression programs along the DV axis: mesoderm on the ventral side, neurectoderm in the lateral regions, and dorsal ectoderm on the dorsal side (Fig. 1A; Hong et al. 2008). For simplicity, we focused on the cell fates at the ends of the gradient, mesoderm, and dorsal ectoderm, which arise during cell cycle 14, around 2-4 h after egg deposition (AED).

The advantage of the Drosophila DV system is that large amounts of cells can be obtained from these two tissues without the need for cell sorting or tissue dissection. This is made possible by the availability of maternal mutants where all embryos in the progeny consist entirely of either mesodermal or dorsal ectodermal precursor cells. In $\mathrm{Tl}$ mutant embryos $T l^{10 b}, \mathrm{Dl}$ activity is uniformly high (but not above wildtype levels), leading to a mesodermal precursor fate (Schneider et al. 1991). In gastrulation defective ( $g d$ ) mutant embryos $g d^{7}, \mathrm{Dl}$ is not activated, resulting in uniformly high signaling activity of the fly BMP2/4 ortholog Decapentaplegic (Dpp) but below wildtype maximum levels (see Ashe and Levine 1999) and the specification of dorsal ectodermal fate in the entire embryo. These mutants have frequently been used in the past because they allow

A

B

C
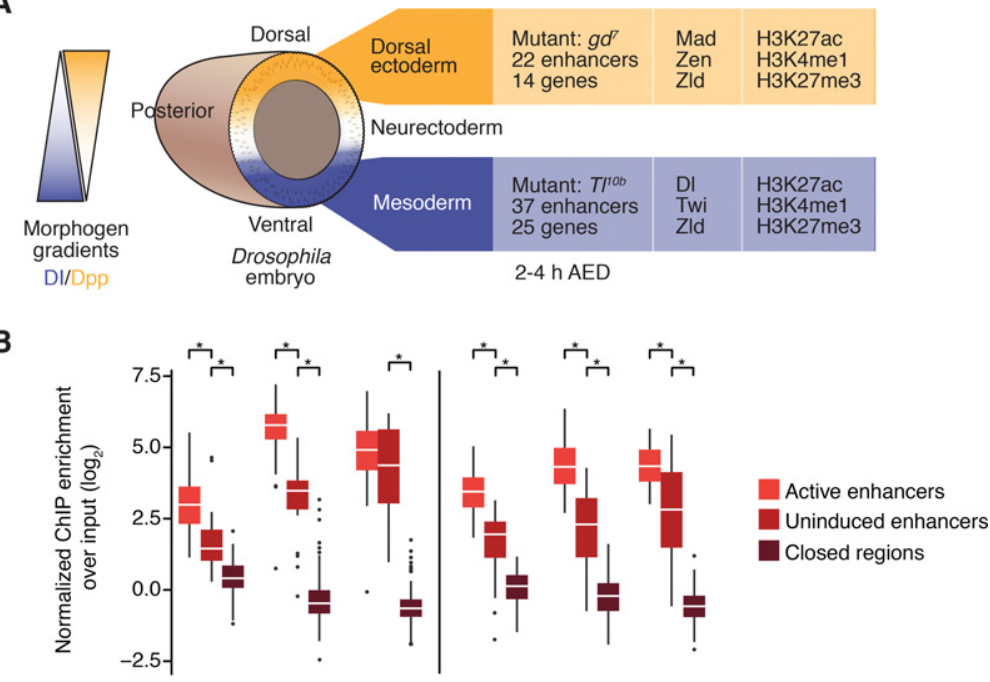

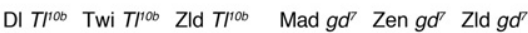

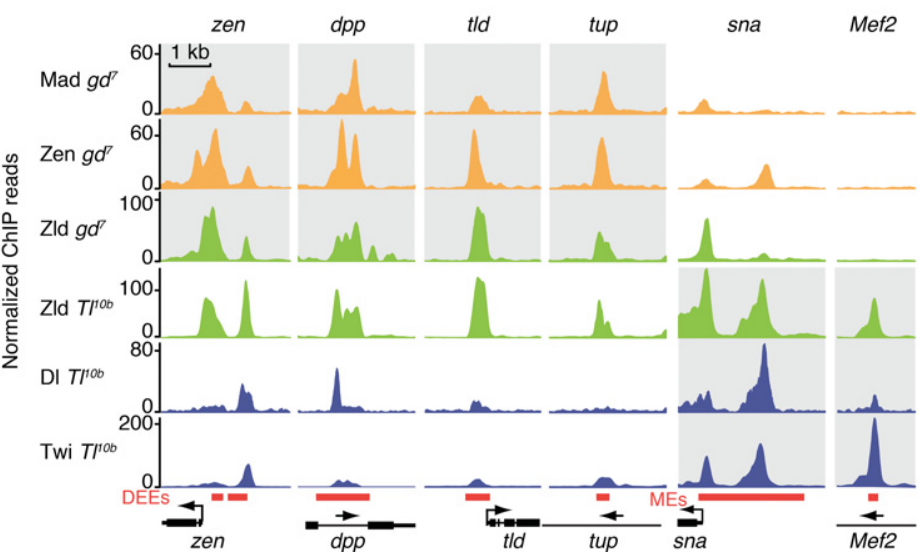

Figure 1. Dorsal-ventral (DV) transcription factors occupy uninduced enhancers at intermediate levels. (A) Overview of the model system of DV patterning in the Drosophila embryo, in which homogeneous cell fates can be obtained through mutants such as $\mathrm{Tl}^{\mathrm{IOb}}$ and $g d^{7}$, for which a large number of tissue-specific enhancers and their target genes are known. A summary of the analyzed ChIP-seq experiments of transcription factors and histone modifications is shown on the right. (AED) After egg deposition. (B) Boxplots of ChIP-seq enrichment over input for the DV transcription factors DI, Twi, Mad, Zen, and Zld at known DV enhancers. The ChIP-seq experiments were performed in $T l^{10 b}$ or $g d^{7}$ or both, dependent on which tissue the transcription factor is expressed in. Note that DV transcription factors occupy uninduced enhancers less than active enhancers but significantly more than closed regions, indicating that uninduced enhancers are accessible. Closed regions are 100 presumptive late enhancers that are inaccessible by DHS (Thomas et al. 2011) at early stages and are enriched for H3K27ac at later embryonic stages (see Methods). Active enhancers are mesoderm enhancers (MEs) in $\mathrm{Tl}^{10 b}$ embryos or dorsal ectoderm enhancers (DEEs) in $g d^{7}$ embryos. Uninduced enhancers are MEs in $g d^{7}$ embryos or DEEs in $\mathrm{Tl}^{10 b} \mathrm{em}$ bryos. Whiskers show 1.5 times the interquartile range, and outliers are shown as dots. Asterisk indicates $P<10^{-3}$ using the Wilcoxon rank-sum test. (C) ChIP-seq binding profiles of the transcription factors at four DEEs and two MEs (red boxes with target genes shown in black) illustrate higher binding at active enhancers (gray shading) but some degree of binding at uninduced enhancers (white background). The DEEs of zen, dpp, and tld are known to be repressed by DI, while the snail (sna) ME is activated by DI (Ip et al. 1992). ChIP-seq reads are normalized to reads per million.

the analysis of patterning across the $\mathrm{Dl}$ activity gradient (e.g., Stathopoulos et al. 2002; Zeitlinger et al. 2007; Holmqvist et al. 2012) and have helped DV patterning become one of the beststudied gene regulatory networks in development.

The DV patterning system also illustrates another important principle of pattern formation, the widespread use and requirement of sequence-specific transcriptional repressors. The extensive genetic screens in Drosophila have shown that transcriptional 
repressors are crucial for the correct interpretation of morphogen gradients, including DV patterning (Ip and Hemavathy 1997; Bier and De Robertis 2015; Briscoe and Small 2015). During DV patterning, $\mathrm{Dl}$ is able to specify three distinct cell fates because, in addition to its role as a transcriptional activator, it can also act as a repressor when certain additional repressive sequences in an enhancer are present next to a Dl motif (Pan and Courey 1992; Jiang et al. 1993). When $\mathrm{Dl}$ is converted into a repressor, it recruits corepressors and histone deacetylases (Dubnicoff et al. 1997; Valentine et al. 1998; Chen et al. 1999; Flores-Saaib et al. 2001; Ratnaparkhi et al. 2006) and dominantly suppresses enhancer activation (Gray and Levine 1996; Dubnicoff et al. 1997). Three cis-regulatory sequences-those regulating dpp, zerknüllt (zen), and tolloid (tld) - have been shown to be ventrally repressed by $\mathrm{Dl}$, allowing spatially restricted activation of these genes on the dorsal side of the embryo (Irish and Gelbart 1987; Rushlow et al. 1987; Ip et al. 1991; Huang et al. 1993; Kirov et al. 1994; Ratnaparkhi et al. 2006).

By using the DV system, we analyzed the state of uninduced enhancers during patterning, including those known to be repressed, and asked whether they correspond to a primed or poised enhancer state.

\section{Results}

\section{Uninduced DV enhancers are accessible to transcription factors} albeit at lower levels

To characterize the enhancer states during DV patterning, we first assembled a list of known DV enhancers that have been verified by transgenic lacZ reporter assays (Supplemental Table S1). We identified 37 mesoderm enhancers (MEs) that remain uninduced in the dorsal ectoderm and 22 dorsal ectoderm enhancers (DEEs) that remain uninduced in the mesoderm (Fig. 1A; for a complete list and references, see Supplemental Material). To validate our experimental system, we performed mRNA-seq experiments on $\mathrm{Tl}^{10 b}$ and $g d^{7}$ embryos at 2-4 h AED. As expected, most genes that were assigned to a known DV enhancer were more highly expressed in the tissue in which the enhancer is active (Supplemental Fig. S1).

We then asked whether uninduced enhancers are accessible to transcription factors and performed ChIP-seq experiments in $T l^{10 b}$ and $g d^{7}$ embryos at 2-4 h AED. Replicate experiments were highly correlated (Supplemental Material). We specifically analyzed DV transcription factors that are required for the cell fate specification of the mesoderm and dorsal ectoderm (Fig. 1A). High Dl activity on the ventral side of the embryo induces expression of Twist (Twi), which together with $\mathrm{Dl}$ activates mesodermal target genes (Jiang et al. 1991; Ip et al. 1992). We therefore analyzed $\mathrm{Dl}$ and Twi occupancy in $T l^{10 b}$ embryos and calculated their enrichments at active MEs and DEEs, which are actively repressed or remain uninduced (Fig. 1B). As a control, we used a set of 100 presumptive late enhancers that are inaccessible ("closed") at 2-4 $\mathrm{h}$ AED but are accessible and marked by H3K27ac in the late embryo (see Methods). Active enhancers had the highest levels of $\mathrm{Dl}$ and Twi, the closed control regions had the lowest levels, and uninduced enhancers had statistically significant intermediate levels of occupancy (Fig. 1B).

Dpp signaling, which activates the transcription factors Mothers against dpp (Mad), and Zen induce dorsal ectodermal fate (Raftery et al. 1995; Rusch and Levine 1997; Lin et al. 2006). We therefore analyzed the occupancy of Mad and Zen in $g d^{7}$ embryos and found that their occupancy at both active DEEs and uninduced MEs was also significantly higher than at the closed control regions (Fig. 1B). Again, their occupancy at uninduced enhancers was significantly lower than at active enhancers (Fig. 1B), further supporting the hypothesis that uninduced enhancers are bound by transcription factors but to a lesser extent than active enhancers.

The observation that uninduced DV enhancers are bound by transcription factors suggests that these enhancers are accessible because they were primed by a pioneer transcription factor. A potential pioneer transcription factor is Zelda (Zld), which is present ubiquitously in the Drosophila early embryo and primes enhancers even before DV patterning begins (Liang et al. 2008; Harrison et al. 2011; Nien et al. 2011). While Zld is required to make some DV enhancers accessible (Yanez-Cuna et al. 2012; Foo et al. 2014; Schulz et al. 2015; Sun et al. 2015), it is not known whether Zld remains bound to uninduced enhancers at the same level as at active enhancers.

We therefore analyzed the occupancy of Zld at active enhancers, uninduced enhancers, and closed regions. The closed regions that we used as controls were not bound by Zld or were bound at very low levels. In contrast, uninduced enhancers remained highly bound by Zld in both tissues, albeit at slightly lower levels than at active enhancers (Fig. 1B). This suggests that Zld primes early enhancers in the entire embryo, whether or not the enhancers are induced. The sometimes-higher levels of Zld at active enhancers compared with uninduced enhancers are consistent with our observation that active enhancers are more accessible to transcription factors than uninduced enhancers.

We next analyzed the three DEEs that are known to be repressed by $\mathrm{Dl}$ in $T l^{10 b}$ mutants (zen, $d p p$, and tld in Fig. 1C). We found that these enhancers follow similar trends as other DV enhancers. When these enhancers are active in $g d^{7}$ embryos, they show high occupancy of Zld, Mad, and Zen, as expected. When they are repressed in $\mathrm{Tl}^{10 b}$ mutants, they are occupied by Zld, Dl, and Twi. Since Twi is an activator and has no known role in repressing these enhancers, this result suggests that repressed enhancers are to some degree accessible to transcription factors, presumably due to the pioneering activity of Zld. Consistent with Zld being critical for enhancer access, in the rare case where Zld does not occupy an uninduced enhancer, other transcription factors are also not bound (e.g., Mef2 in Fig. 1C).

Taken together, these results suggest that uninduced enhancers are frequently primed and bound by transcription factors, albeit to a lower degree than in the active state. This level of accessibility might allow these enhancers to be inactive but responsive to changes in signaling and transcription factor activity.

\section{Uninduced enhancers are marked by H3K4mel and low H3K27ac and thus carry a poised enhancer signature}

Having identified three distinct enhancer states, we next investigated their histone modification status. We performed ChIP-seq experiments with antibodies against H3K27ac and H3K4me1 in both mutant embryos and calculated the enrichment $( \pm 500 \mathrm{bp}$ from enhancer center) at all active and uninduced enhancers from both mutants, as well as closed regions as a control.

Uninduced enhancers had overall significantly higher levels of H3K27ac compared with closed control regions $\left(P<10^{-6}\right.$, Wilcoxon rank-sum test) (Fig. 2A), but their levels were significantly lower than at active enhancers $\left(P<10^{-6}\right.$, Wilcoxon ranksum test) (Fig. 2A). Indeed, when we plotted the relative difference 
for each enhancer between the two tissues, the difference in H3K27ac levels between active and uninduced enhancers became more significant $\left(P<10^{-9}\right.$, Wilcoxon rank-sum test) (Fig. 2B). This suggests that uninduced enhancers have low levels of H3K27ac and that the levels significantly increase when the enhancers are active.

When we analyzed H3K4me1 levels, we found that uninduced enhancers are also enriched for H3K4me1 significantly

A

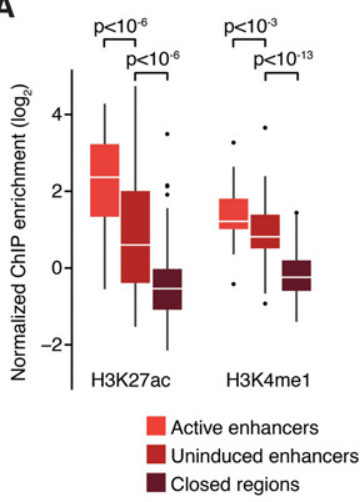

B

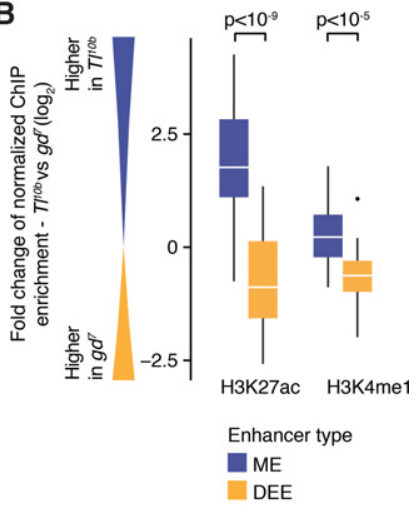

C
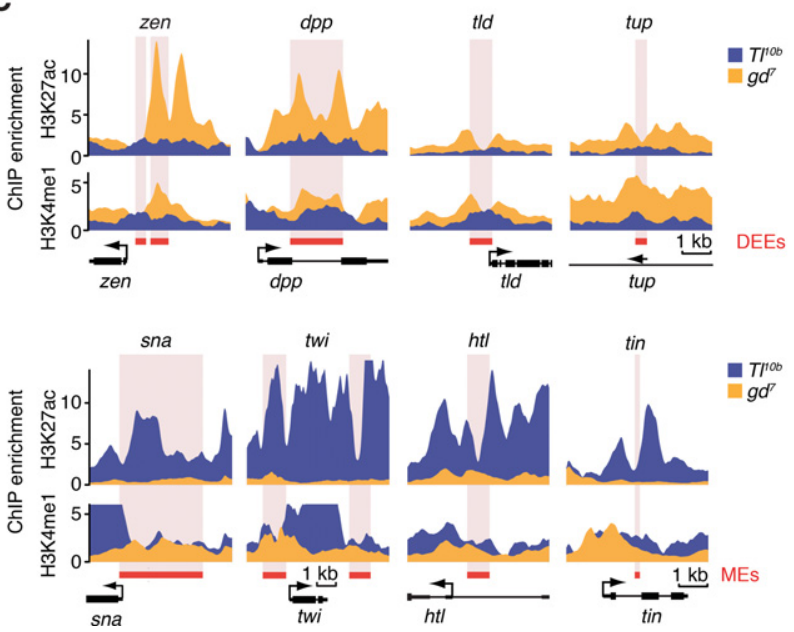

Figure 2. The histone modifications at uninduced enhancers resemble the poised enhancer signature. (A) Boxplots of normalized H3K27ac and H3K4me1 ChIP-seq enrichments show that all uninduced DV enhancers ( $n=59$, from both mutants) have lower H3K27ac enrichment levels than the same enhancers in the active state, yet the levels of $\mathrm{H} 3 \mathrm{~K} 4 \mathrm{me} 1$ are significantly above closed regions ( $n=100$, same as in Fig. 1B), consistent with a poised enhancer signature. Whiskers show 1.5 times the interquartile range, and outliers are shown as dots. Significance between enhancer groups was determined using the Wilcoxon rank-sum test. (B) Boxplots of the fold-change of normalized histone modification ChIP-seq enrichments between mutant embryos show that H3K27ac and H3K4me1 levels are higher at active enhancers versus uninduced enhancers: The majority of MEs (blue) have higher $\mathrm{H} 3 \mathrm{~K} 27 \mathrm{ac}$ enrichment in the $\mathrm{Tl}^{10 \mathrm{~b}}$ mutant than in the $g d^{7}$ mutant (thus $\log _{2} T I^{10 b}-\log _{2} g d^{7}$ above 0 ), while the inverse is true for dorsal ectodermal enhancers (DEEs; yellow). Significance between MEs and DEEs was determined using the Wilcoxon rank-sum test. (C) Binding profiles of histone modification ChIP-seq enrichments show higher enrichment of $\mathrm{H} 3 \mathrm{~K} 27 \mathrm{ac}$ and $\mathrm{H} 3 \mathrm{~K} 4 \mathrm{me} 1$ when the enhancer is active. At the four DEEs, the levels are higher in $\mathrm{gd}^{7}$ (yellow), while at four MEs, the levels are higher in $\mathrm{Tl}^{10 \mathrm{~b}}$ (blue). The red box and the pink shading show the position of the enhancers, and the black arrow indicates the position and orientation of transcription start sites. The $1 \mathrm{~kb}$ scale bar shown for the tin region also applies to the sna and $h t /$ region. above the levels of the control $\left(P<10^{-13}\right.$, Wilcoxon rank-sum test) (Fig. 2A), consistent with a poised enhancer signature. However, H3K4me1 enrichments were slightly lower in the uninduced state than in the active state $\left(P<10^{-3}\right.$, Wilcoxon rank-sum test) (Fig. 2A). This small but consistent difference became more significant when analyzing the relative difference in H3K4me1 at enhancers $\left(P<10^{-5}\right.$, Wilcoxon rank-sum test) (Fig. 2B). The profiles of H3K4me1 at individual enhancers also confirm that H3K4me1 is more highly enriched at active enhancers (Fig. 2C). This finding is unexpected since H3K4me1 is used as a marker for both poised and active enhancers, but closer examination reveals that it is consistent with previous data (Rada-Iglesias et al. 2011; Bonn et al. 2012). The higher levels of H3K4me1 could potentially also be connected to the increased accessibility of active enhancers.

Finally, we specifically examined the three enhancers known to be repressed by $\mathrm{Dl}$ (zen, $d p p$, and tld in Fig. 2C) but found their histone signature of H3K4me1 and low H3K27ac to be indistinguishable from other uninduced enhancers. Thus, the poised enhancer signature is also characteristic for enhancers regulated by transcriptional repressors. Whether there is a histone modification that is specifically associated with transcriptional repressors is not known. H3K27me3 is a well-studied repressive mark, but it is deposited by Polycomb group proteins, which are not known to associate with sequence-specific transcriptional repressors (Simon and Kingston 2013).

\section{H3K27me3 is not a good marker for uninduced enhancers or sequence-specific repressors}

The Polycomb-repressive mark H3K27me3 has been observed at poised enhancers (Rada-Iglesias et al. 2011) or repressed enhancers (Schwartz et al. 2006; Tolhuis et al. 2006; Oktaba et al. 2008; Bonn et al. 2012) but has not specifically been implicated in embryonic DV patterning because Polycomb group mutants are difficult to analyze in the early Drosophila embryo (Pelegri and Lehmann 1994).

When we analyzed H3K27me3 ChIP-seq data in $T l^{10 b}$ and $g d^{7}$ embryos, we found remarkably variable levels of H3K27me3 at DV enhancers. Some enhancers had very high levels of H3K27me3, while more than half of them had no enrichment above background (Fig. 3A). Despite the variance, however, there was a significant trend for enhancers to have higher H3K27me3 levels in the uninduced versus active state $\left(P<10^{-2}\right.$, Wilcoxon rank-sum test) (Fig. 3B), consistent with previous findings (Bonn et al. 2012).

Examination of individual DV enhancers confirms clear differences in H3K27me3 levels between the uninduced and active state in regions where the levels of H3K27me3 are high (Fig. 3C). However, H3K27me3 marks are distributed over broad regions, as expected (Schwartz et al. 2006; Tolhuis et al. 2006); the differences in $\mathrm{H} 3 \mathrm{~K} 27 \mathrm{me} 3$ include the transcribed regions and thus are not specific to DV enhancers (Fig. 3C). This questions whether an enhancer's state directly regulates the surrounding levels of H3K27me3 or may instead affect H3K27me3 levels more indirectly through its effect on gene activation. Indeed, an anti-correlation between H3K27me3 and transcriptional status has been observed previously (Klymenko and Muller 2004; Papp and Muller 2006; Tolhuis et al. 2006; Gaertner et al. 2012), and recent mammalian studies provide direct evidence that transcription status affects the levels of H3K27me3 (Riising et al. 2014; Beltran et al. 2016; Hosogane et al. 2016). 
A

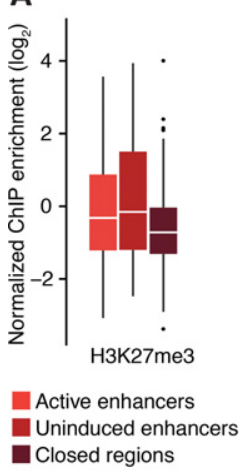

C

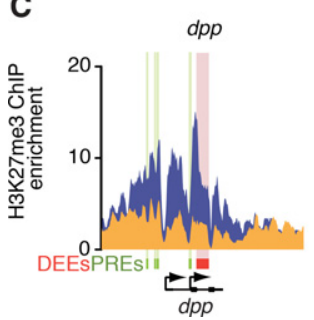

B

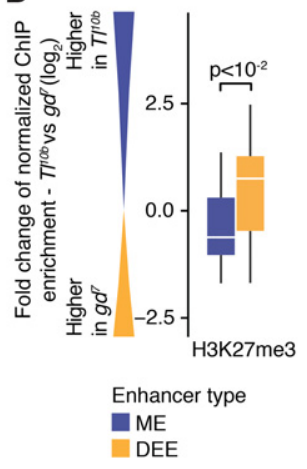

D DV enhancers Zld-bound regions

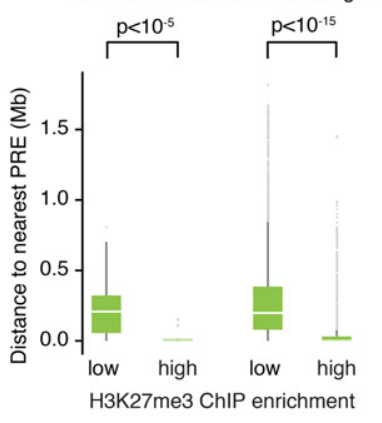

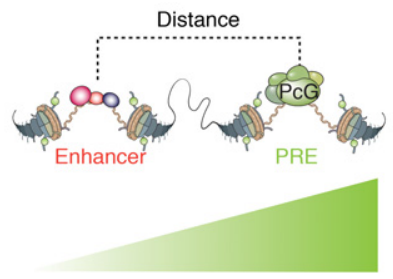

H3K27me3 levels correlate with the distance to the nearest PRE
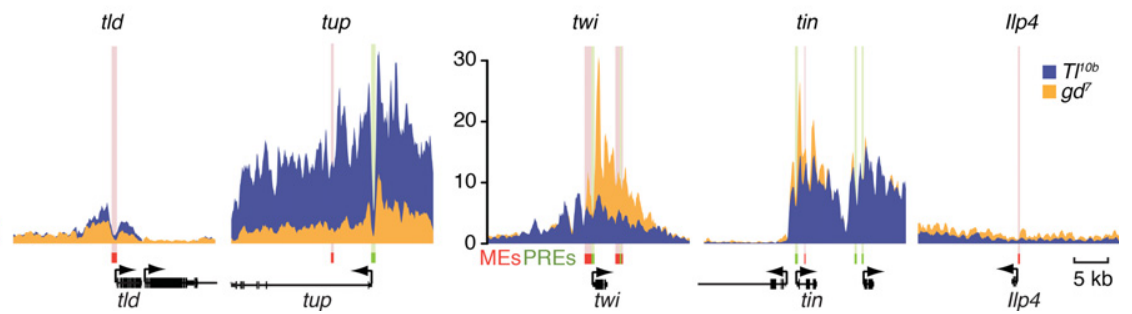

Figure 3. H3K27me3 levels are higher at uninduced enhancers but correlate more strongly with distance to the nearest PRE. (A) Boxplots show a wide range of different $\mathrm{H} 3 \mathrm{~K} 27 \mathrm{me} 3$ levels at the different enhancer states, with no significant differences between them as determined by the Wilcoxon rank-sum test. (B) The fold-change difference in H3K27me3 enrichment between DV mutants shows that H3K27me3 at individual enhancers tends to be higher in the uninduced state versus active state. Significance was determined using the Wilcoxon rank-sum test. (C) H3K27me3 ChIP-seq enrichment profiles for three DEEs and three MEs illustrate clear differences between mutants (yellow vs. blue). H3K27me3 enrichment levels are highest near putative Polycomb response elements (PREs; green). Enhancers are shown as red boxes with pink shading. (D) Boxplots showing the distance of enhancers to the nearest PRE, dependent on whether they have low or high H3K27me3 enrichment levels. For DV enhancers with low H3K27me3 enrichment (below twofold enrichment, $n=39$ ), the distances between enhancers and putative PREs are much larger than for those with high H3K27me3 levels (above twofold enrichment, $n=20$ ). This is also true for Zld-bound regions, which include a large number of putative early Drosophila enhancers (low H3K27me $n=14,4425$, high H3K27me3 $n=2720$ ). Zld-bound regions are the union of Zld ChIP-seq peaks in $\mathrm{Tl}^{10 \mathrm{~b}}$ and $\mathrm{gd}^{7}$ with at least twofold enrichment in either tissue. Putative PREs are defined as the overlap between Pc and GAF regions $(n=602)$. Whiskers show 1.5 times the interquartile range, and outliers are shown as dots.

If transcription reduces $\mathrm{H} 3 \mathrm{~K} 27 \mathrm{me} 3$, what determines whether H3K27me3 is present in that region in the first place? Broad regions of H3K27me3 are catalyzed from specific nucleation sites in the DNA called Polycomb Responsive Elements (PREs) (Simon et al. 1993; Muller and Kassis 2006). In Drosophila, Polycomb group proteins are recruited to PREs by a combination of DNA-binding factors, including GAGA factor (GAF; also known as Trithorax-like or $\operatorname{Trl}$ ) (Strutt et al. 1997). We therefore identified high-confidence PREs through the co-occupancy of GAF, which is not specific for PREs but gives high signal in ChIP experiments, and Polycomb (Pc) itself, which is indirectly bound to DNA but which is highly specific for PREs (Schuettengruber et al. 2009, 2014).

If the levels of H3K27me3 at enhancers depend on nearby PREs, we expect that DV enhancers with high H3K27me3 enrichment will be located closer to PREs than those without. Indeed, the median distance between DV enhancers with high H3K27me3 and the closest PRE is $<10 \mathrm{~kb}$, while for DV enhancers without H3K27me3 enrichment, the median distance to a PRE is $\sim 200 \mathrm{~kb}$ $\left(P<10^{-5}\right.$, Wilcoxon rank-sum test) (Fig. 3D). The correlation between PREs and $\mathrm{H} 3 \mathrm{~K} 27 \mathrm{me} 3$ can also be observed at individual DV enhancer regions, where the levels of H3K27me3 often peak close to PREs (Fig. 3C). Finally, the correlation between PREs and H3K27me3 is not specific for DV enhancers since the same trend was observed for all Zld-bound regions (Fig. 3D). These results strongly support the traditional model that high levels of H3K27me3 depend on nearby PREs.
The anti-correlation between gene activation and $\mathrm{H} 3 \mathrm{~K} 27 \mathrm{me} 3$ suggests that active enhancers can reduce the H3K27me3 mark deposited by nearby PREs. To consider alternative models, we also probed the possibility that repressors at enhancers might directly promote H3K27me3 deposition. However, the known Dl-repressed enhancers did not stand out in their H3K27me3 profile compared with other uninduced enhancers (Fig. 3C). For example, the Dl-repressed $d p p$ enhancer has very high levels of H3K27me3 in the repressed state, while another Dl-repressed enhancer, that of $t l d$, has much lower levels. Furthermore, high levels are also observed at enhancers that are not repressed by Dl, including tup. Thus, while the levels of H3K27me3 correlate with the presence of PREs, they do not correlate with Dl-dependent repression. While we cannot rule out a subtle role for repressors in modulating H3K27me3 levels, our data suggest that the strongest determinants of H3K27me3 levels are nearby PREs and lack of gene activation. Therefore, H3K27me3 cannot be considered a specific marker for uninduced or repressed enhancers.

\section{Poised DV enhancers are specifically generated during tissue patterning and are not poised for future activation}

Our results so far suggest that uninduced enhancers have a histone signature that is indistinguishable from the poised enhancer signature described in mammals, with or without H3K27me3. This

\section{Genome Research}

www.genome.org 
raises the question whether the Drosophila DV enhancers are at some point poised for future activation.

We first considered the possibility that DV enhancers are poised prior to activation, when the enhancers are primed by Zld before Dl-dependent transcription begins. Based on a careful time-course analysis (Li et al. 2014), the primed DV enhancers do not show the poised signature until cell cycle 14 , when DV patterning begins. While H3K27ac accumulates very early and gradually, H3K4me1 and H3K27me3 show a strong increase only during cell cycle 14 (Fig. 4A). This suggests that the DV enhancers do not have a poised enhancer signature when they are primed prior to activation.

We next considered whether the DV enhancers are poised for activation beyond DV patterning during later stages of embryogenesis. This seems unlikely since enhancers are in the vast majority stage specific. To nevertheless test the possibility, we analyzed DNase I hypersensitivity (DHS) data across embryogenesis (Thomas et al. 2011). We found that DV enhancers are most accessible during DV patterning (stages 5 and 9), when they are active, and become less accessible at subsequent stages (Fig. 4B). This argues against additional roles for these enhancers past DV patterning.

Taken together, our analysis suggests that the poised enhancer signature of low H3K27ac and some H3K4me1 is specifically generated during DV patterning at uninduced enhancers. There is no evidence that it precedes enhancer activation, arguing that it marks spatial rather than temporal regulation in this system.

\section{Discussion}

The poised enhancer signature as a marker for spatial enhancer regulation

We found that DV enhancers acquire the poised enhancer signature (low H3K27ac, some H3K4me1) specifically during tissue patterning (model in Fig. 5). Before DV patterning, these enhancers are primed by the pioneer transcription factor Zld and have a very different enhancer signature (some H3K27ac but no H3K4me1). It is unclear whether this enhancer signature is typical for primed enhancers since the priming occurs during the maternal-to-zygotic transition. Nevertheless, it clearly shows that the poised enhancer signature does not precede enhancer activation in the DV system and thus is specifically generated in the tissue in which the enhancers are not activated. During subsequent stages, the DV enhancers close again, perhaps because key transcription factors such as Zld are no longer present (Kanodia et al. 2012). It is also possible that repressive chromatin modifying complexes help to decommission enhancers to reduce their activity in subsequent developmental programs (Whyte et al. 2012).

The Drosophila DV developmental system therefore demonstrates that poised enhancers are not always poised for activation in the future but may mark enhancers that did not receive the signal for activation during tissue patterning. These uninduced enhancers are accessible to transcription factors and thus likely remain responsive to the appropriate developmental signals for some time. This allows cells to adjust to changes in signals from surrounding cells during pattern formation. However, in the absence of appropriate signals, a poised enhancer does not become active and instead proceeds directly to a closed state. Thus, poised enhancers in our system may be inducible during the time in which tissue patterning takes place, but their function is not to serve as a target for future patterning events.

In mammalian systems, a fraction of enhancers have been shown to be poised prior to activation (Creyghton et al. 2010; Rada-Iglesias et al. 2011; Wamstad et al. 2012; Wang et al. 2015). This may be because the primed state already resembles the poised state or because enhancer activation occurs in a more sequential fashion by multiple patterning signals. However, many poised enhancers do not become active later, and many active enhancers are not poised before activation (Wamstad et al. 2012; Choukrallah et al. 2015). This suggests that many mammalian enhancers may also simply be poised as a side effect of tissue patterning, as we have observed in the Drosophila DV system. They are poised because they were not activated in a specific developmental context and they do not have another opportunity for activation in the future course of development.

\section{A role for repressors in keeping poised enhancers inactive}

We found that the three DV enhancers that are actively repressed by $\mathrm{Dl}$ have the poised enhancer signature. This raises the possibility that sequence-specific repressors actively help generate the poised enhancer signature and prevent these enhancers from becoming active.

In support of this hypothesis, the poised enhancer signature fits strikingly well with previous mechanistic studies on repression on individual loci in Drosophila. Transcriptional repressors such as Dl have been reported to reduce the occupancy of transcription factors and remove histone acetylation through the recruitment of corepressors and histone deacetylases (Chen et al. 1999; Kulkarni and Arnosti 2005; Sekiya and Zaret 2007; Winkler et al. 2010; Li and Arnosti 2011). Thus, the low levels of $\mathrm{H} 3 \mathrm{~K} 27 \mathrm{ac}$ and the reduced access to transcription factors that we observe for zen, $d p p$, and $t l d$ must be to some extent the result of Dl-mediated repression.
Figure 4. DV enhancers are not poised for future activation. $(A)$ Histone modification levels at DV enhancers during the maternal-to-zygotic transition (Li et al. 2014) show that H3K27ac levels are accumulating early and gradually during development, and thus, some $\mathrm{H} 3 \mathrm{~K} 27 \mathrm{ac}$ is present during enhancer priming by Zld at cell cycles 8 and 12. In contrast, H3K4me1 and H3K27me3, which mark poised , are only detectable after Dl-dependent transcription begins at stage 5 or cell cycle 14 (shaded in gray). Data are shown as average ChIP-seq signal in a 1-kb window centered on each enhancer. $(B)$ Boxplots of DNase I hypersensitivity (DHS) at DV enhancers during embryogenesis show that all DV enhancers are most accessible during stages 5 and 9 when DV patterning takes place (shaded in gray), and become less accessible at subsequent stages. The DHS score is the average signal per enhancer region derived from the data by Thomas et al. (2011). Whiskers show 1.5 times the interquartile range, and outliers are shown as dots. 


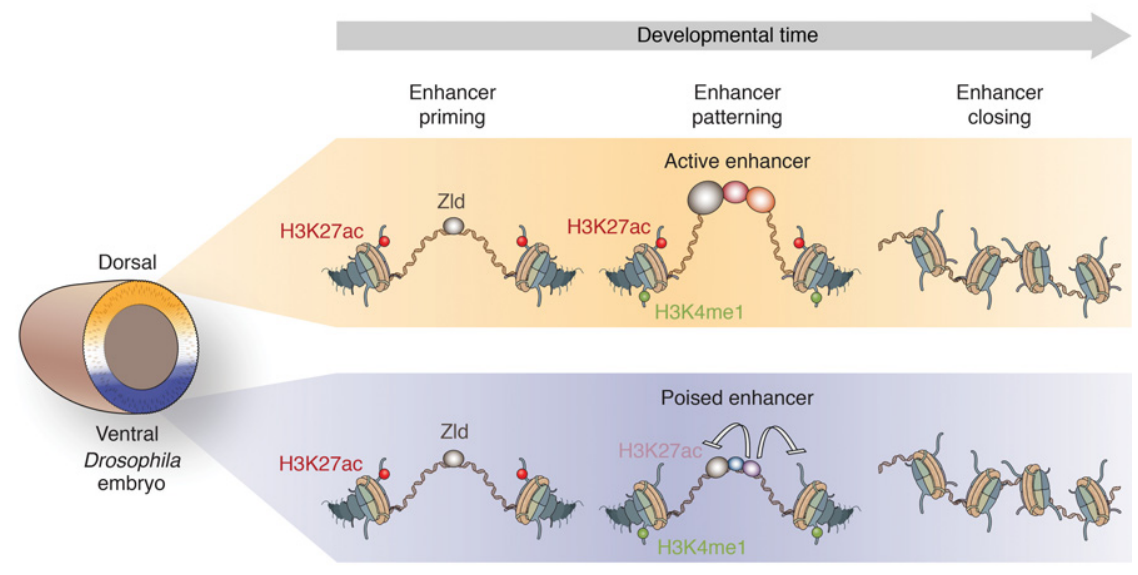

Figure 5. Summary model showing the poised enhancer signature arising specifically during tissue patterning in the Drosophila DV system. Before DV patterning begins in the Drosophila embryo, DV enhancers are primed by the pioneer transcription factor Zld and have low levels of H3K27ac. During DV patterning, DV enhancers may be active in one tissue but repressed by sequence-specific repressors in another tissue and thus remain uninduced. As has been studied extensively, these repressors recruit histone deacetylases, remove $\mathrm{H} 3 \mathrm{~K} 27 \mathrm{ac}$, and thus produce the poised enhancer signature. After DV patterning is complete, DV enhancers gradually close, thus enhancers with the poised enhancer signature also close and are not poised for future activation.

An even more intriguing hypothesis is that the poised enhancer signature is generally the product of enhancer-bound repressors. This would explain why the Dl-repressed enhancers did not stand out in their histone modification signature compared with other uninduced enhancers. There are many sequence-specific repressors that modulate DV patterning, including Snail (Kosman et al. 1991; Leptin 1991), Capicua (Jimenez et al. 2000; Helman et al. 2012), Suppressor of Hairless (Morel and Schweisguth 2000; Ozdemir et al. 2014), and Schnurri (Crocker and Erives 2013). Thus, it is feasible that repressors play a central role in preventing the inappropriate activation of accessible enhancers. Below, we discuss a number of reasons why this is not only plausible but also an attractive model.

Based on ChIP-seq data, regions of open chromatin are surprisingly susceptible to unspecific transcription factor binding (Moorman et al. 2006; MacArthur et al. 2009). Many transcription factors have strong activation domains, putting accessible enhancer regions at risk for unwarranted activation. For example, Zld has high transactivation potential and likely recruits the histone acetyl transferase CBP that mediates H3K27ac (Hamm et al. 2015; Stampfel et al. 2015), consistent with H3K27ac being present during enhancer priming by Zld (Li et al. 2014). Strikingly, we showed that Zld is still bound to DV enhancers during DV patterning, yet these enhancers have no or low H3K27ac and remain uninduced in parts of the embryo. The simplest explanation for this observation is that activation by Zld is repressed or "quenched" by repressors in these cells. Thus, repressors would serve to remove the histone acetylation that Zld induced during enhancer priming and prevent the accumulation of this activating mark throughout DV patterning.

Another reason is that the pattern by which poised enhancers occur during lineage development is consistent with the expected widespread use of repressors in signaling and tissue patterning. In addition to sequence-specific repressors employed during tissue patterning, most developmental signal transduction pathways have their own dedicated mechanism to repress target genes in the absence of signaling activity (Barolo and Posakony 2002; Affolter et al. 2008). The fact that these signal transduction pathways are highly conserved across evolution supports the notion that repression is an integral part of enhancer regulation.

\section{Mechanistic implications for poised enhancers with repressors}

Finally, the involvement of repressors in keeping poised enhancers inactive has important mechanistic implications and predictions that have not been discussed to our knowledge. An active battle between activators and repressors in controlling histone acetylation at the poised state implies a monocycle between opposing enzymes, thus acetylation by acetyl transferases and deacetylation by deacetylases. Analogous to phosphorylation-dephosphorylation dynamics found at some enzymes, such monocycles can create switch-like behaviors and were therefore termed zero-order ultrasensitivity (Goldbeter and Koshland 1981; Ferrell and Ha 2014). In other words, repressors could make enhancers ultrasensitive in their response to activation signals.

Such zero-order ultrasensitivity predicts that a repressed enhancer can be very sensitive to activation, so that only a small amount of activation signal can lead to significant induction (Melen et al. 2005; Ferrell and Ha 2014). This is particularly important in the response to morphogen gradients, where a certain threshold concentration leads to enhancer activation and expression of downstream target genes. At the same time, zero-order ultrasensitivity also implies that a strongly repressed state is relatively stable against inappropriate activation. For example, the role of Polycomb repression, found at important developmental genes, could be to keep enhancers in the repressed regime until they are activated.

In summary, a model in which poised enhancers are actively balanced between activators and repressors could provide a mechanism to explain the ultrasensitive response of enhancers to patterning signals. This could explain the widespread occurrence of a distinct poised enhancer state during tissue patterning. Since the model makes clear mechanistic predictions, it opens new avenues for further exploration and tests in the future.

\section{Methods}

\section{Stock maintenance and embryo collection}

The fly stock $T l^{10 b}$ was obtained from the Bloomington stock center (no. 30914). The $g d^{7}$ stock was kindly provided by Mike Levine. $g d^{7} / g d^{7}$ females and $g d^{7} / Y$ males were collected from the $g d^{7} /$ winscy, hs-hid stock after heat shocking 1 day old larvae twice for $1 \mathrm{~h}$ at $37^{\circ} \mathrm{C}, 24 \mathrm{~h}$ apart. T(1;3)OR60/ $\mathrm{Tl}^{10 b}, e^{1}$ females and $\mathrm{Tl}^{10 b} /$ TM3, $e^{1}, S b^{1}, S e r^{1}$ males were selected from the stock consisting of genotypes $\mathrm{Tl}^{10 b} / \mathrm{TM} 3, e^{1}, \mathrm{Sb}^{1}, \mathrm{Ser}^{1}$ and T(1;3)OR60/TM3, $e^{1}$, $S b^{1}, S e r^{1}$. Oregon-R embryos were used for wild-type ChIP-seq samples. Embryos were collected from cages on apple juice plates for 2 $\mathrm{h}$ at $25^{\circ} \mathrm{C}$ and then aged for another $2 \mathrm{~h}$ at $25^{\circ} \mathrm{C}$ (to produce the

\section{Genome Research}

www.genome.org 
time window of 2-4 h AED). Embryos were dechorionated with $100 \%$ bleach and cross-linked for 15 min with 1.8\% formaldehyde (final concentration in water phase) for ChIP-seq experiments.

\section{ChIP-seq experiments}

ChIP-seq experiments were performed as previously described (He et al. 2011, 2015) with 100 mg embryos per ChIP and with more extensive washing with RIPA buffer after ChIP incubation to reduce background. The antibodies for ChIP-seq were custom-generated by Genscript (Dl aa 39-346, Mad aa 148-455, full-length Zen, Zld aa 1117-1327, GAF aa 1-382 of isoform PA) or by Covance (Twi aa 340-490) or were commercially available: H3K27ac (Active motif, no. 39133), H3K4me1 (Active motif, no. 39635), H3K27me3 (Active motif, no. 39155), and Pc (Santa Cruz, no. sc-25762). $\mathrm{Tl}^{10 b}$ embryos were used for ChIP-seq for Dl, Twi, Zld, H3K27ac, H3K4me1, and H3K27me3; wild-type embryos for GAF and Pc; and $g d^{7}$ embryos for Mad, Zen, Zld, H3K27ac, H3K4me1, and H3K27me3.

\section{Library preparation}

Different combinations of library preparation kits and barcodes were used for ChIP-seq and mRNA-seq library preparations (Supplemental Table S3), and libraries were prepared according to the manufacturer's instructions. ChIP-seq libraries were prepared from 5-15 ng ChIP DNA or $100 \mathrm{ng}$ input DNA and sequenced on the GAIIX (Illumina) or the HiSeq 2500 (Illumina).

\section{ChIP-seq data processing}

Sequenced ChIP-seq reads were aligned to UCSC Drosophila melanogaster reference genome $\mathrm{dm} 3$ using Bowtie v1.1.1 (Langmead et al. 2009), allowing up to two mismatches and retaining only uniquely aligning reads. Aligned reads were extended to the sample's estimated fragment size using the chipseq Bioconductor library (Huber et al. 2015).

Replicates of genotype-specific whole-cell extract (WCE) input samples for $T l^{10 b}$ and $g d^{7}$ were merged, and these merged inputs were used for enrichment calculations and peak calling.

Transcription factor ChIP-seq enrichments over input within each enhancer were calculated within a 201-bp window centered at the transcription factor's ChIP-seq signal summit. Enrichment calculations were normalized for both differences in read count and estimated fragment size between ChIP and input samples. Histone modification enrichments were calculated similarly but using a 1001-bp window centered on the enhancer region. The replicates for each transcription factor and histone modification with the highest median enrichment were used for further analysis. To assess sample quality, MACS2 (Zhang et al. 2008) was run on all samples with their corresponding tissue's input control and these nondefault parameters: macs2 callpeak -t ip.bam -c wce. bam -g dm -keep-dup=all.

Peak counts for each sample can be found in Supplemental Table S3.

\section{Normalization of histone modification ChIP-seq data}

Fold-change in ChIP-seq enrichments of H3K27ac, H3K4me1, and H3K27me3 between $T l^{10 b}$ and $g d^{7}$ were normalized to account for differences in ChIP-seq efficiency. The normalization factor for each histone modification was determined by the median foldchange in ChIP-seq enrichment at MACS2 peaks that were detected in both mutant embryos.

\section{mRNA-seq experiments}

Embryos were dechorionated with $100 \%$ bleach and stored at $-80^{\circ}$ $\mathrm{C}$ until used. Total mRNA was extracted from 50-100 mg 2-4 h AED $T l^{10 b}$ embryos in duplicates and $g d^{7}$ embryos in triplicates using the Maxwell total mRNA purification kit (Promega, no. AS1225) according to the manufacturer's instructions. PolyA-mRNA was isolated using Dynabeads oligo(dT) (Life Technologies, no. 61002). Libraries were prepared following the instructions of the TruSeq DNA sample preparation kit (Illumina, no. FC-121-2001) and sequenced on the HiSeq 2500 (Illumina) or the NextSeq 500 (Illumina).

\section{mRNA-seq data processing}

mRNA-seq reads were aligned against the FlyBase r5.57 genome and gene annotations using TopHat2 v2.0.14 (Kim et al. 2013) with the following nondefault parameters: tophat - $G$ fb557 genes.gtf -I 20 -I 5000 --no-coverage-search --segment-length 25.

Cuffdiff, from Cufflinks v2.2.1 (Trapnell et al. 2010), was used to determine transcript abundance and differential expression between $T l^{10 b}$ and $g d^{7}$ mutants.

\section{List of known DV enhancers}

A list of known DV enhancers was assembled from the literature. Enhancers were only included if lac $Z$ reporter assays confirmed a DV-biased expression pattern. The full list of known DV enhancer regions and the respective publication that shows the staining of the enhancer's lac $Z$ reporter assay can be found in Supplemental Table S1. A target gene was assigned to DV enhancers only if the enhancer's expression domain overlapped and resembled the gene's expression domain (Supplemental Material). For this purpose, published mRNA in situ hybridization data from the Berkeley Drosophila Genome Project (BDGP) (Tomancak et al. 2002, 2007; Hammonds et al. 2013) database were used for enhancers identified by Kvon et al. (2012) and Ozdemir et al. (2011). For some of these enhancers, no target gene was identified with confidence, and thus those enhancers were not included in mRNA-seq analysis shown in Supplemental Figure S1 (Supplemental Material).

Definition of active enhancers, uninduced enhancers, and closed regions

Active enhancers are MEs in the mutant $T l^{10 b}$ and DEEs in $g d^{7}$ embryos. Uninduced enhancers are MEs in $g d^{7}$ embryos and DEEs in $T l^{10 b}$ embryos. A total of 100 closed regions were randomly selected from published DHS regions (see more details below) (Thomas et al. 2011) based on the following criteria: They are only accessible at stage 14 and not in any of the earlier stages; they overlap with peaks from published H3K27ac ChIP-seq at 14-16 h AED in wild-type embryos (obtained from modMine: modENCODE ID:4120) (Contrino et al. 2012); and they do not overlap with a TSS (2 kb centered on a TSS).

\section{ChIP-seq binding profile displays at single genes}

Single gene profiles of histone modifications show ChIP-seq enrichment values over input calculated using a 501-bp sliding window. Transcription factor profiles are shown in reads per million.

\section{Identification of putative PREs}

Putative PREs were defined as regions that result from overlapping Pc and GAF peaks (minimum 50-bp overlap) from ChIP-seq in wild-type $2-4 \mathrm{~h}$ AED embryos. Overlapping regions were combined to one putative PRE region, resulting in 602 putative PREs. 
For Zld-bound regions, peaks were called by MACS2 (Zhang et al. 2008) on $T l^{10 b}$ and $g d^{7}$ ChIP-seq samples, and the union from the $T l^{10 b}$ and $g d^{7}$ peaks with at least twofold enrichment over background in one tissue was identified. Enrichment of H3K27me3 was calculated in a 1001-bp region centered at each Zld peak. Both known enhancers and Zld regions were divided into H3K27me3 "low" and "high" groups based on an enrichment threshold of twofold below or above input, respectively. Coordinates for putative PREs can be found in Supplemental Table S2, and distances of known DV enhancers to the closest putative PRE can be found in Supplemental Table S1.

\section{DHS at known DV enhancers}

DHS data sets (Thomas et al. 2011) were downloaded from the USCS Genome Browser: http://hgdownload.cse.ucsc.edu/gbdb/ dm3/bdtnp/bdtnpDnaseS5R9481.bw; S9R9127.bw, S10R8816. bw, S11R9485.bw, and S14R9477.bw. Average DHS signal per base was calculated for all known DV enhancers at each of the five embryonic stages by summing the number of DHS reads that overlap each enhancer and dividing by the enhancer's width in base pairs.

\section{Histone modification data during maternal-to-zygotic transition}

Processed H3K27ac, H3K4me1, and H3K27me3 ChIP-seq data in the early embryo ( $\mathrm{Li}$ et al. 2014) were obtained from GEO (GSE58935). ChIP-seq data are shown as average signal in a 1001-bp region centered at each enhancer.

\section{Data access}

The whole-genome sequence data from this study have been submitted to the NCBI Gene Expression Omnibus (GEO; http://www. ncbi.nlm.nih.gov/geo/) under accession number GSE68983. In addition, all data analysis performed in this study, including raw data, processed data, software tools, and analysis scripts, has been reproduced in a publically accessible Linux virtual machine. For details, see http://research.stowers.org/zeitlingerlab/data.html.

\section{Acknowledgments}

We thank Robb Krumlauf, Chris Rushlow, Robin Fropf, Malini Natarajan, and Arnob Dutta for feedback on the manuscript; Kai Chen for providing the Pc ChIP-seq data; Irina Pushel for help with the Zld ChIP-seq data sets; and Mark Miller for scientific illustration. This work was funded by the Foundation for the National Institutes of Health (NIH) New Innovator Award 1DP2 OD00456101 to J.Z. and the Stowers Institute for Medical Research. N.K.'s contribution was part of her PhD thesis with the Open University, UK.

\section{References}

Affolter M, Pyrowolakis G, Weiss A, Basler K. 2008. Signal-induced repression: the exception or the rule in developmental signaling? Dev Cell 15: $11-22$.

Ashe HL, Levine M. 1999. Local inhibition and long-range enhancement of Dpp signal transduction by Sog. Nature 398: 427-431.

Barolo S, Posakony JW. 2002. Three habits of highly effective signaling pathways: principles of transcriptional control by developmental cell signaling. Genes Dev 16: 1167-1181.

Beltran M, Yates CM, Skalska L, Dawson M, Reis FP, Viiri K, Fisher CL, Sibley CR, Foster BM, Bartke T, et al. 2016. The interaction of PRC2 with RNA or chromatin is mutually antagonistic. Genome Res 26: 896-907.

Bier E, De Robertis EM. 2015. EMBRYO DEVELOPMENT. BMP gradients: a paradigm for morphogen-mediated developmental patterning. Science 348: aaa5838.
Bonn S, Zinzen RP, Girardot C, Gustafson EH, Perez-Gonzalez A, Delhomme N, Ghavi-Helm Y, Wilczynski B, Riddell A, Furlong EE. 2012. Tissue-specific analysis of chromatin state identifies temporal signatures of enhancer activity during embryonic development. Nat Genet 44: 148-156.

Briscoe J, Small S. 2015. Morphogen rules: design principles of gradient-mediated embryo patterning. Development 142: 3996-4009.

Chen G, Fernandez J, Mische S, Courey AJ. 1999. A functional interaction between the histone deacetylase Rpd3 and the corepressor Groucho in Drosophila development. Genes Dev 13: 2218-2230.

Choukrallah MA, Song S, Rolink AG, Burger L, Matthias P. 2015. Enhancer repertoires are reshaped independently of early priming and heterochromatin dynamics during B cell differentiation. Nat Commun 6: 8324 .

Contrino S, Smith RN, Butano D, Carr A, Hu F, Lyne R, Rutherford K, Kalderimis A, Sullivan J, Carbon S, et al. 2012. modMine: flexible access to modENCODE data. Nucleic Acids Res 40: D1082-D1088.

Creyghton MP, Cheng AW, Welstead GG, Kooistra T, Carey BW, Steine EJ, Hanna J, Lodato MA, Frampton GM, Sharp PA, et al. 2010. Histone H3K27ac separates active from poised enhancers and predicts developmental state. Proc Natl Acad Sci 107: 21931-21936.

Crocker J, Erives A. 2013. A Schnurri/Mad/Medea complex attenuates the dorsal-twist gradient readout at vnd. Dev Biol 378: 64-72.

Dubnicoff T, Valentine SA, Chen G, Shi T, Lengyel JA, Paroush Z, Courey AJ. 1997. Conversion of dorsal from an activator to a repressor by the global corepressor Groucho. Genes Dev 11: 2952-2957.

Ernst J, Kheradpour P, Mikkelsen TS, Shoresh N, Ward LD, Epstein CB, Zhang X, Wang L, Issner R, Coyne M, et al. 2011. Mapping and analysis of chromatin state dynamics in nine human cell types. Nature 473: 43-49.

Ferrell JE Jr, Ha SH. 2014. Ultrasensitivity part I: Michaelian responses and zero-order ultrasensitivity. Trends Biochem Sci 39: 496-503.

Flores-Saaib RD, Jia S, Courey AJ. 2001. Activation and repression by the Cterminal domain of Dorsal. Development 128: 1869-1879.

Foo SM, Sun Y, Lim B, Ziukaite R, O'Brien K, Nien CY, Kirov N, Shvartsman SY, Rushlow CA. 2014. Zelda potentiates morphogen activity by increasing chromatin accessibility. Curr Biol 24: 1341-1346.

Gaertner B, Johnston J, Chen K, Wallaschek N, Paulson A, Garruss AS, Gaudenz K, De Kumar B, Krumlauf R, Zeitlinger J. 2012. Poised RNA polymerase II changes over developmental time and prepares genes for future expression. Cell Rep 2: 1670-1683.

Goldbeter A, Koshland DE Jr. 1981. An amplified sensitivity arising from covalent modification in biological systems. Proc Natl Acad Sci 78: 6840-6844.

Gray S, Levine M. 1996. Short-range transcriptional repressors mediate both quenching and direct repression within complex loci in Drosophila. Genes Dev 10: 700-710.

Hamm DC, Bondra ER, Harrison MM. 2015. Transcriptional activation is a conserved feature of the early embryonic factor Zelda that requires a cluster of four zinc fingers for DNA binding and a low-complexity activation domain. J Biol Chem 290: 3508-3518.

Hammonds AS, Bristow CA, Fisher WW, Weiszmann R, Wu S, Hartenstein V, Kellis M, Yu B, Frise E, Celniker SE. 2013. Spatial expression of transcription factors in Drosophila embryonic organ development. Genome Biol 14: R140.

Harrison MM, Li XY, Kaplan T, Botchan MR, Eisen MB. 2011. Zelda binding in the early Drosophila melanogaster embryo marks regions subsequently activated at the maternal-to-zygotic transition. PLoS Genet 7: e1002266.

He Q, Bardet AF, Patton B, Purvis J, Johnston J, Paulson A, Gogol M, Stark A, Zeitlinger J. 2011. High conservation of transcription factor binding and evidence for combinatorial regulation across six Drosophila species. Nat Genet 43: 414-420.

He Q, Johnston J, Zeitlinger J. 2015. ChIP-nexus enables improved detection of in vivo transcription factor binding footprints. Nat Biotechnol 33: $395-401$.

Helman A, Lim B, Andreu MJ, Kim Y, Shestkin T, Lu H, Jimenez G, Shvartsman SY, Paroush Z. 2012. RTK signaling modulates the Dorsal gradient. Development 139: 3032-3039.

Holmqvist PH, Boija A, Philip P, Crona F, Stenberg P, Mannervik M. 2012. Preferential genome targeting of the CBP co-activator by Rel and Smad proteins in early Drosophila melanogaster embryos. PLoS Genet 8: e1002769.

Hong JW, Hendrix DA, Papatsenko D, Levine MS. 2008. How the Dorsal gradient works: insights from postgenome technologies. Proc Natl Acad Sci 105: 20072-20076.

Hosogane M, Funayama R, Shirota M, Nakayama K. 2016. Lack of transcription triggers H3K27me3 accumulation in the gene body. Cell Rep 16: 696-706.

Huang JD, Schwyter DH, Shirokawa JM, Courey AJ. 1993. The interplay between multiple enhancer and silencer elements defines the pattern of decapentaplegic expression. Genes Dev 7: 694-704.

\section{Genome Research}

www.genome.org 
Huber W, Carey VJ, Gentleman R, Anders S, Carlson M, Carvalho BS, Bravo HC, Davis S, Gatto L, Girke T, et al. 2015. Orchestrating high-throughput genomic analysis with Bioconductor. Nat Methods 12: 115-121.

Ip YT, Hemavathy K. 1997. Drosophila development: delimiting patterns by repression. Curr Biol 7: R216-R218.

Ip YT, Kraut R, Levine M, Rushlow CA. 1991. The dorsal morphogen is a sequence-specific DNA-binding protein that interacts with a long-range repression element in Drosophila. Cell 64: 439-446.

Ip YT, Park RE, Kosman D, Yazdanbakhsh K, Levine M. 1992. dorsal-twist interactions establish snail expression in the presumptive mesoderm of the Drosophila embryo. Genes Dev 6: 1518-1530.

Irish VF, Gelbart WM. 1987. The decapentaplegic gene is required for dorsal-ventral patterning of the Drosophila embryo. Genes Dev 1: 868-879.

Jiang J, Kosman D, Ip YT, Levine M. 1991. The dorsal morphogen gradient regulates the mesoderm determinant twist in early Drosophila embryos. Genes Dev 5: 1881-1891.

Jiang J, Cai H, Zhou Q, Levine M. 1993. Conversion of a dorsal-dependent silencer into an enhancer: evidence for dorsal corepressors. EMBO J 12: 3201-3209.

Jimenez G, Guichet A, Ephrussi A, Casanova J. 2000. Relief of gene repression by torso RTK signaling: role of capicua in Drosophila terminal and dorsoventral patterning. Genes Dev 14: 224-231.

Junion G, Spivakov M, Girardot C, Braun M, Gustafson EH, Birney E, Furlong EE. 2012. A transcription factor collective defines cardiac cell fate and reflects lineage history. Cell 148: 473-486.

Kanodia JS, Liang HL, Kim Y, Lim B, Zhan M, Lu H, Rushlow CA, Shvartsman SY. 2012. Pattern formation by graded and uniform signals in the early Drosophila embryo. Biophys J 102: 427-433.

Kim D, Pertea G, Trapnell C, Pimentel H, Kelley R, Salzberg SL. 2013. TopHat2: accurate alignment of transcriptomes in the presence of insertions, deletions and gene fusions. Genome Biol 14: R36.

Kirov N, Childs S, O'Connor M, Rushlow C. 1994. The Drosophila dorsal morphogen represses the tolloid gene by interacting with a silencer element. Mol Cell Biol 14: 713-722.

Klymenko T, Muller J. 2004. The histone methyltransferases Trithorax and Ash1 prevent transcriptional silencing by Polycomb group proteins. EMBO Rep 5: 373-377.

Kosman D, Ip YT, Levine M, Arora K. 1991. Establishment of the mesodermneuroectoderm boundary in the Drosophila embryo. Science 254: $118-122$.

Kulkarni MM, Arnosti DN. 2005. cis-regulatory logic of short-range transcriptional repression in Drosophila melanogaster. Mol Cell Biol 25: 3411-3420.

Kvon EZ, Stampfel G, Yanez-Cuna JO, Dickson BJ, Stark A. 2012. HOT regions function as patterned developmental enhancers and have a distinct cis-regulatory signature. Genes Dev 26: 908-913.

Langmead B, Trapnell C, Pop M, Salzberg SL. 2009. Ultrafast and memoryefficient alignment of short DNA sequences to the human genome. Genome Biol 10: R25.

Leptin M. 1991. twist and snail as positive and negative regulators during Drosophila mesoderm development. Genes Dev 5: 1568-1576.

Li LM, Arnosti DN. 2011. Long- and short-range transcriptional repressors induce distinct chromatin states on repressed genes. Curr Biol 21: 406-412

Li XY, MacArthur S, Bourgon R, Nix D, Pollard DA, Iyer VN, Hechmer A, Simirenko L, Stapleton M, Luengo Hendriks CL, et al. 2008 Transcription factors bind thousands of active and inactive regions in the Drosophila blastoderm. PLoS Biol 6: e27.

Li XY, Harrison MM, Villalta JE, Kaplan T, Eisen MB. 2014. Establishment of regions of genomic activity during the Drosophila maternal to zygotic transition. eLife 3: e03737.

Liang HL, Nien CY, Liu HY, Metzstein MM, Kirov N, Rushlow C. 2008. The zinc-finger protein Zelda is a key activator of the early zygotic genome in Drosophila. Nature 456: 400-403.

Lin MC, Park J, Kirov N, Rushlow C. 2006. Threshold response of C15 to the Dpp gradient in Drosophila is established by the cumulative effect of Smad and Zen activators and negative cues. Development 133: $4805-4813$.

MacArthur S, Li XY, Li J, Brown JB, Chu HC, Zeng L, Grondona BP, Hechmer A, Simirenko L, Keranen SV, et al. 2009. Developmental roles of 21 Drosophila transcription factors are determined by quantitative differences in binding to an overlapping set of thousands of genomic regions. Genome Biol 10: R80.

Melen GJ, Levy S, Barkai N, Shilo BZ. 2005. Threshold responses to morphogen gradients by zero-order ultrasensitivity. Mol Syst Biol 1: 20050028.

Moorman C, Sun LV, Wang J, de Wit E, Talhout W, Ward LD, Greil F, Lu XJ, White KP, Bussemaker HJ, et al. 2006. Hotspots of transcription factor colocalization in the genome of Drosophila melanogaster. Proc Natl Acad Sci 103: 12027-12032.
Morel V, Schweisguth F. 2000. Repression by Suppressor of Hairless and activation by Notch are required to define a single row of single-minded expressing cells in the Drosophila embryo. Genes Dev 14: 377-388.

Muller J, Kassis JA. 2006. Polycomb response elements and targeting of Polycomb group proteins in Drosophila. Curr Opin Genet Dev 16: $476-484$.

Nien CY, Liang HL, Butcher S, Sun Y, Fu S, Gocha T, Kirov N, Manak JR, Rushlow C. 2011. Temporal coordination of gene networks by Zelda in the early Drosophila embryo. PLoS Genet 7: e1002339.

Oktaba K, Gutierrez L, Gagneur J, Girardot C, Sengupta AK, Furlong EE, Muller J. 2008. Dynamic regulation by Polycomb group protein complexes controls pattern formation and the cell cycle in Drosophila. Dev Cell 15: 877-889.

Ozdemir A, Fisher-Aylor KI, Pepke S, Samanta M, Dunipace L, McCue K, Zeng L, Ogawa N, Wold BJ, Stathopoulos A. 2011. High resolution mapping of Twist to DNA in Drosophila embryos: efficient functional analysis and evolutionary conservation. Genome Res 21: 566-577.

Ozdemir A, Ma L, White KP, Stathopoulos A. 2014. Su(H)-mediated repression positions gene boundaries along the dorsal-ventral axis of Drosophila embryos. Dev Cell 31: 100-113.

Pan D, Courey AJ. 1992. The same dorsal binding site mediates both activation and repression in a context-dependent manner. EMBO $J$ 11: $1837-1842$.

Papp B, Muller J. 2006. Histone trimethylation and the maintenance of transcriptional ON and OFF states by trxG and PcG proteins. Genes Dev 20: 2041-2054.

Pelegri F, Lehmann R. 1994. A role of Polycomb group genes in the regulation of gap gene expression in Drosophila. Genetics 136: 1341-1353.

Rada-Iglesias A, Bajpai R, Swigut T, Brugmann SA, Flynn RA, Wysocka J. 2011. A unique chromatin signature uncovers early developmental enhancers in humans. Nature 470: 279-283.

Raftery LA, Twombly V, Wharton K, Gelbart WM. 1995. Genetic screens to identify elements of the decapentaplegic signaling pathway in Drosophila. Genetics 139: 241-254

Ratnaparkhi GS, Jia S, Courey AJ. 2006. Uncoupling dorsal-mediated activation from dorsal-mediated repression in the Drosophila embryo. Development 133: 4409-4414.

Riising EM, Comet I, Leblanc B, Wu X, Johansen JV, Helin K. 2014. Gene silencing triggers Polycomb repressive complex 2 recruitment to $\mathrm{CpG}$ islands genome wide. Mol Cell 55: 347-360.

Rusch J, Levine M. 1997. Regulation of a dpp target gene in the Drosophila embryo. Development 124: 303-311.

Rushlow C, Frasch M, Doyle H, Levine M. 1987. Maternal regulation of zerknüllt: a homoeobox gene controlling differentiation of dorsal tissues in Drosophila. Nature 330: 583-586.

Sandmann T, Girardot C, Brehme M, Tongprasit W, Stolc V, Furlong EE. 2007. A core transcriptional network for early mesoderm development in Drosophila melanogaster. Genes Dev 21: 436-449.

Schneider DS, Hudson KL, Lin TY, Anderson KV. 1991. Dominant and recessive mutations define functional domains of Toll, a transmembrane protein required for dorsal-ventral polarity in the Drosophila embryo. Genes Dev 5: 797-807.

Schuettengruber B, Ganapathi M, Leblanc B, Portoso M, Jaschek R, Tolhuis B, van Lohuizen M, Tanay A, Cavalli G. 2009. Functional anatomy of Polycomb and trithorax chromatin landscapes in Drosophila embryos. PLoS Biol 7: e13.

Schuettengruber B, Oded Elkayam N, Sexton T, Entrevan M, Stern S, Thomas A, Yaffe E, Parrinello H, Tanay A, Cavalli G. 2014. Cooperativity, specificity, and evolutionary stability of Polycomb targeting in Drosophila. Cell Rep 9: 219-233.

Schulz KN, Bondra ER, Moshe A, Villalta JE, Lieb JD, Kaplan T, McKay DJ, Harrison MM. 2015. Zelda is differentially required for chromatin accessibility, transcription factor binding, and gene expression in the early Drosophila embryo. Genome Res 25: 1715-1726.

Schwartz YB, Kahn TG, Nix DA, Li XY, Bourgon R, Biggin M, Pirrotta V. 2006. Genome-wide analysis of Polycomb targets in Drosophila melanogaster. Nat Genet 38: 700-705.

Sekiya T, Zaret KS. 2007. Repression by Groucho/TLE/Grg proteins: Genomic site recruitment generates compacted chromatin in vitro and impairs activator binding in vivo. Mol Cell 28: 291-303.

Shlyueva D, Stampfel G, Stark A. 2014. Transcriptional enhancers: from properties to genome-wide predictions. Nat Rev Genet 15: 272-286.

Simon JA, Kingston RE. 2013. Occupying chromatin: Polycomb mechanisms for getting to genomic targets, stopping transcriptional traffic, and staying put. Mol Cell 49: 808-824.

Simon J, Chiang A, Bender W, Shimell MJ, O'Connor M. 1993. Elements of the Drosophila bithorax complex that mediate repression by Polycomb group products. Dev Biol 158: 131-144.

Spitz F, Furlong EE. 2012. Transcription factors: from enhancer binding to developmental control. Nat Rev Genet 13: 613-626. 
Stampfel G, Kazmar T, Frank O, Wienerroither S, Reiter F, Stark A. 2015. Transcriptional regulators form diverse groups with context-dependent regulatory functions. Nature 528: 147-151.

Stathopoulos A, Van Drenth M, Erives A, Markstein M, Levine M. 2002. Whole-genome analysis of dorsal-ventral patterning in the Drosophila embryo. Cell 111: 687-701.

Stergachis AB, Neph S, Reynolds A, Humbert R, Miller B, Paige SL, Vernot B, Cheng JB, Thurman RE, Sandstrom R, et al. 2013. Developmental fate and cellular maturity encoded in human regulatory DNA landscapes. Cell 154: 888-903.

Strutt H, Cavalli G, Paro R. 1997. Co-localization of Polycomb protein and GAGA factor on regulatory elements responsible for the maintenance of homeotic gene expression. EMBO J 16: 3621-3632.

Sun Y, Nien CY, Chen K, Liu HY, Johnston J, Zeitlinger J, Rushlow C. 2015. Zelda overcomes the high intrinsic nucleosome barrier at enhancers during Drosophila zygotic genome activation. Genome Res 25: 1703-1714

Thomas S, Li XY, Sabo PJ, Sandstrom R, Thurman RE, Canfield TK, Giste E, Fisher W, Hammonds A, Celniker SE, et al. 2011. Dynamic reprogramming of chromatin accessibility during Drosophila embryo development. Genome Biol 12: R43.

Tolhuis B, de Wit E, Muijrers I, Teunissen H, Talhout W, van Steensel B, van Lohuizen M. 2006. Genome-wide profiling of PRC1 and PRC2 Polycomb chromatin binding in Drosophila melanogaster. Nat Genet 38: 694-699.

Tomancak P, Beaton A, Weiszmann R, Kwan E, Shu S, Lewis SE, Richards S, Ashburner M, Hartenstein V, Celniker SE, et al. 2002. Systematic determination of patterns of gene expression during Drosophila embryogenesis. Genome Biol 3: RESEARCH0088.

Tomancak P, Berman BP, Beaton A, Weiszmann R, Kwan E, Hartenstein V, Celniker SE, Rubin GM. 2007. Global analysis of patterns of gene expression during Drosophila embryogenesis. Genome Biol 8: R145.

Trapnell C, Williams BA, Pertea G, Mortazavi A, Kwan G, van Baren MJ, Salzberg SL, Wold BJ, Pachter L. 2010. Transcript assembly and quantification by RNA-Seq reveals unannotated transcripts and isoform switching during cell differentiation. Nat Biotechnol 28: 511-515.
Valentine SA, Chen G, Shandala T, Fernandez J, Mische S, Saint R, Courey AJ. 1998. Dorsal-mediated repression requires the formation of a multiprotein repression complex at the ventral silencer. Mol Cell Biol 18: 6584-6594.

Wamstad JA, Alexander JM, Truty RM, Shrikumar A, Li F, Eilertson KE, Ding H, Wylie JN, Pico AR, Capra JA, et al. 2012. Dynamic and coordinated epigenetic regulation of developmental transitions in the cardiac lineage. Cell 151: 206-220.

Wang A, Yue F, Li Y, Xie R, Harper T, Patel NA, Muth K, Palmer J, Qiu Y, Wang J, et al. 2015. Epigenetic priming of enhancers predicts developmental competence of hESC-derived endodermal lineage intermediates. Cell Stem Cell 16: 386-399.

Whyte WA, Bilodeau S, Orlando DA, Hoke HA, Frampton GM, Foster CT, Cowley SM, Young RA. 2012. Enhancer decommissioning by LSD1 during embryonic stem cell differentiation. Nature 482: 221-225.

Winkler CJ, Ponce A, Courey AJ. 2010. Groucho-mediated repression may result from a histone deacetylase-dependent increase in nucleosome density. PLoS One 5: e10166.

Yanez-Cuna JO, Dinh HQ, Kvon EZ, Shlyueva D, Stark A. 2012. Uncovering cis-regulatory sequence requirements for context-specific transcription factor binding. Genome Res 22: 2018-2030.

Zaret KS, Carroll JS. 2011. Pioneer transcription factors: establishing competence for gene expression. Genes Dev 25: 2227-2241.

Zeitlinger J, Zinzen RP, Stark A, Kellis M, Zhang H, Young RA, Levine M. 2007. Whole-genome ChIP-chip analysis of Dorsal, Twist, and Snail suggests integration of diverse patterning processes in the Drosophila embryo. Genes Dev 21: 385-390.

Zentner GE, Tesar PJ, Scacheri PC. 2011. Epigenetic signatures distinguish multiple classes of enhancers with distinct cellular functions. Genome Res 21: 1273-1283.

Zhang Y, Liu T, Meyer CA, Eeckhoute J, Johnson DS, Bernstein BE, Nusbaum C, Myers RM, Brown M, Li W, et al. 2008. Model-based Analysis of ChIP-Seq (MACS). Genome Biol 9: R137.

Received May 7, 2016; accepted in revised form November 8, 2016.

\section{Genome Research}




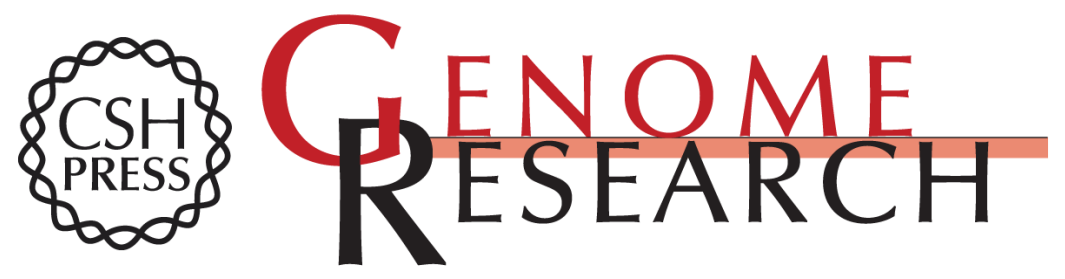

\section{Drosophila poised enhancers are generated during tissue patterning with the help of repression}

Nina Koenecke, Jeff Johnston, Qiye He, et al.

Genome Res. 2017 27: 64-74 originally published online November 14, 2016

Access the most recent version at doi:10.1101/gr.209486.116

Supplemental Material

References

Open Access

Creative Commons

License

Email Alerting Service
http://genome.cshlp.org/content/suppl/2016/12/14/gr.209486.116.DC1

This article cites 102 articles, 43 of which can be accessed free at: http://genome.cshlp.org/content/27/1/64.full.html\#ref-list-1

Freely available online through the Genome Research Open Access option.

This article, published in Genome Research, is available under a Creative Commons License (Attribution-NonCommercial 4.0 International), as described at http://creativecommons.org/licenses/by-nc/4.0/.

Receive free email alerts when new articles cite this article - sign up in the box at the top right corner of the article or click here.

\section{Affordable, Accurate Sequencing.}

